\title{
OPPORTUNITY WELDING ENERGY IN CAPACITORS OF AMORPHOUS ALLOY FOILS, $\mathrm{Ni}_{63} \mathrm{Cr}_{12} \mathrm{Fe}_{4} \mathrm{Si}_{8} \mathrm{~B}_{13}$
}

\author{
Dragoş DRĂGĂNESCU-ANGHEL, Cosmin CODREAN, Dragoş BUZDUGAN, Ion MITELEA, \\ Mircea BURCĂ
}

\author{
Mechanical Faculty-Politehnica University of Timisoara, Timisoara, Romania, EU, \\ dragos.draganescuanghel@student.upt.ro,.cosmin.codrean@upt.ro,dragos.buzdugan@upt.ro, \\ ion.mitelea@upt.ro,mircea.burca@upt.ro
}

https://doi.org/10.37904/metal.2021.4227

\begin{abstract}
Amorphous alloys have attracted considerable attention as new structural materials due to their excellent mechanical properties, high wear and corrosion resistance, magnetic properties, and electrical resistivity. However, most of them become brittle by crystallization, structural relaxation, or by separating intermetallic phases during heating. That is why the traditional methods of melt welding based on the introduction of a large amount of heat and the production of intermetallic phases on the interface between the seam and the thermally influenced area are not suitable for joining these materials. Such welding methods can lead to the destruction of the amorphous structure and to the worsening of the useful properties of the welded joints.

In this paper, a new method of joining amorphous alloys is investigated based on the modification of the welding energy for different values of the capacity of the capacitor, keeping constant the pressing force and the transformation ratio. The examination of the quality of the welded joints was done by macro graphic analyzes, mechanical tests, and calorimetry with differential scanning. (Differential Scanning Calorimeter)
\end{abstract}

Keywords: Amorphous alloy, welding, microstructure

\section{INTRODUCTION}

Welding of thin sheets and foils with a thickness $s<0.5 \mathrm{~mm}$, is a difficult problem, mainly due to the high danger of burning and penetration of the material, but also the high tendency of deformation due to low rigidity [1]. Therefore, the welding of these materials requires rigorous control of the energy in the form of heat introduced into the welded joint, respectively the rapid dissipation of heat from the joint area by welding in the device, a measure that simultaneously helps to control deformations.

The problem is even more difficult when it comes to welding films made of amorphous materials, due to their specific electrical properties, as well as the very small thicknesses - the order of microns that these materials generally have. In addition, the literature contains extremely little data on the technique of welding metallic materials with amorphous structures [2-5].

The paper presents the results of experimental research on spot welding with energy stored in capacitors of foils from an amorphous material having a thickness of $50 \mu \mathrm{m}(0.05 \mathrm{~mm})$.

\section{THE EXPERIMENTAL PROGRAM}

Figure 1 shows the welding machine used to conduct the experimental program. It consists of the following components: the frame, the welding transformer, the external circuit, the mobile arm drive system, the capacitor bank, the electrical installation of the welding circuit, and the control circuit. 


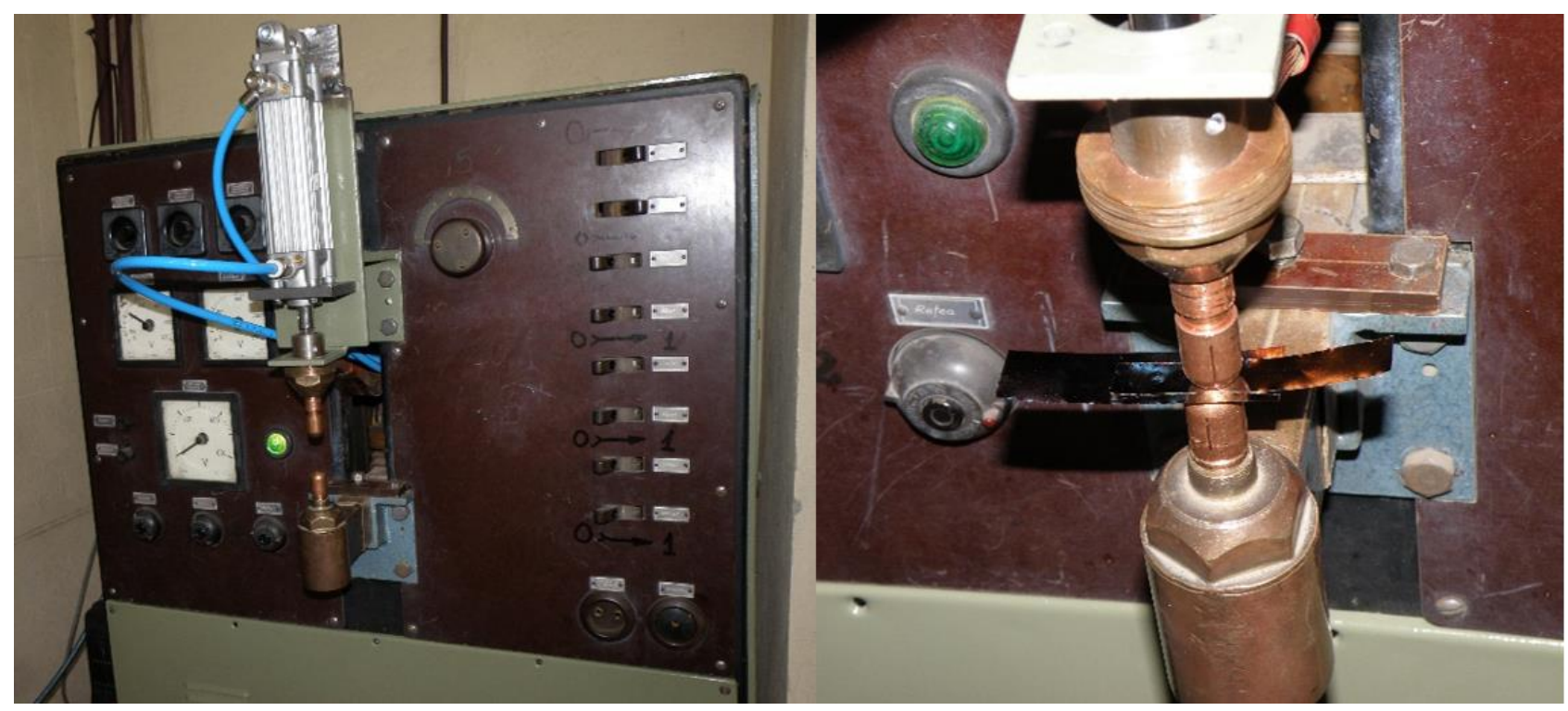

Figure 1 Welding machine with energy stored in capacitors

The main technical characteristics of the equipment are:

- $\quad$ supply voltage: $230 \mathrm{~V}$, at $50 \mathrm{~Hz}$;

- $\quad$ maximum charging voltage of the capacitor bank: 500V;

- $\quad$ maximum energy accumulated in the capacitor bank: $1.25 \mathrm{~kJ}$ (at a total capacity of $10000 \mu \mathrm{F}$ );

- $\quad$ own battery capacity: $4000 \mu \mathrm{F}$, plus $6000 \mu \mathrm{F}$ auxiliary battery capacity, adjustable according to technological needs;

- $\quad$ maximum pressing force (tightening) of the electrodes: $600 \mathrm{~N}$;

- $\quad$ mobile electrode stroke: $100 \mathrm{~mm}$;

- $\quad$ mobile electrode actuation mode: pneumatic at $P_{\max }=0.8 \mathrm{MPa}$.

The charging voltage of the capacitor bank is adjusted in 6 steps by changing the number of turns in the transformer mayor. The capacity of the capacitor bank can be adjusted by parallelizing capacitors of different capacities. The clamping force of the electrodes is regulated by means of the pressure regulator in the FRU group, by changing the pressure of the compressed air. The transformation ratio of the welding transformer is adjusted by connecting in series or in parallel the turns of the primary winding in the following ratios: $150-125$ $-100-75-50-25$.

The experimental researches mainly focused on two aspects, on the one hand obtaining qualitatively acceptable welded points, without defects such as piercing the material or gluing it to the electrodes affecting the surface (aesthetics) of the welded point, and on the other hand, ensuring the resistance of the welded point to the mechanical tests to which it is to be subjected (traction, shear, etc.).

This was achieved by successively modifying the welding energy $E$, for different values of the capacitance capacity respectively of the charging voltage, keeping the pressing force and the transformation ratio constant. If the welding energy is too low, only a superficial gluing of the components takes place, without mechanical resistance, and if the energy is too high, the components break through, and the foils are glued to the copper electrodes.

The technological welding parameters that gave the best results are:

- $\quad$ charging voltage: $300 \mathrm{~V}$;

- $\quad$ capacitor capacity: $40 \mu \mathrm{F}$;

- $\quad$ pressing force: $0.5 \mathrm{kN}$; 
- $\quad$ compressed air pressure: $0.4 \mathrm{MPa}$;

- $\quad$ welding energy: $1.8 \mathrm{~J}$.

\section{EVALUATION OF EXPERIMENTAL RESULTS}

The external appearance of the welded points is presented in Figure 2. There is a good reproducibility of the welded points, with barely perceptible fingerprints, without affecting the surface of the foils, which attests to a good dosage of the energy introduced during welding.

The paper must contain conclusion. The conclusion should summarize the findings and explain the implications of the paper. Conclusion contains no new data or findings.

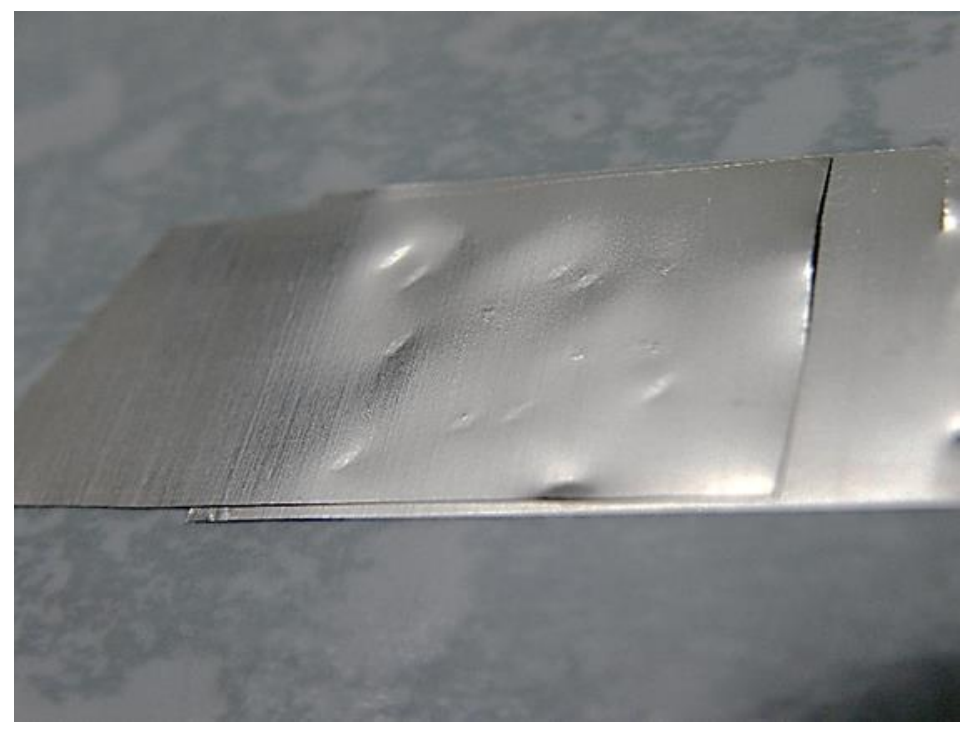

Figure 2 Exterior appearance of the welded spots

The macro graphic image of a cross-section through the welded joint (Figure 3) demonstrates that in the area of the welded kernel there are no defects of metallic continuity.

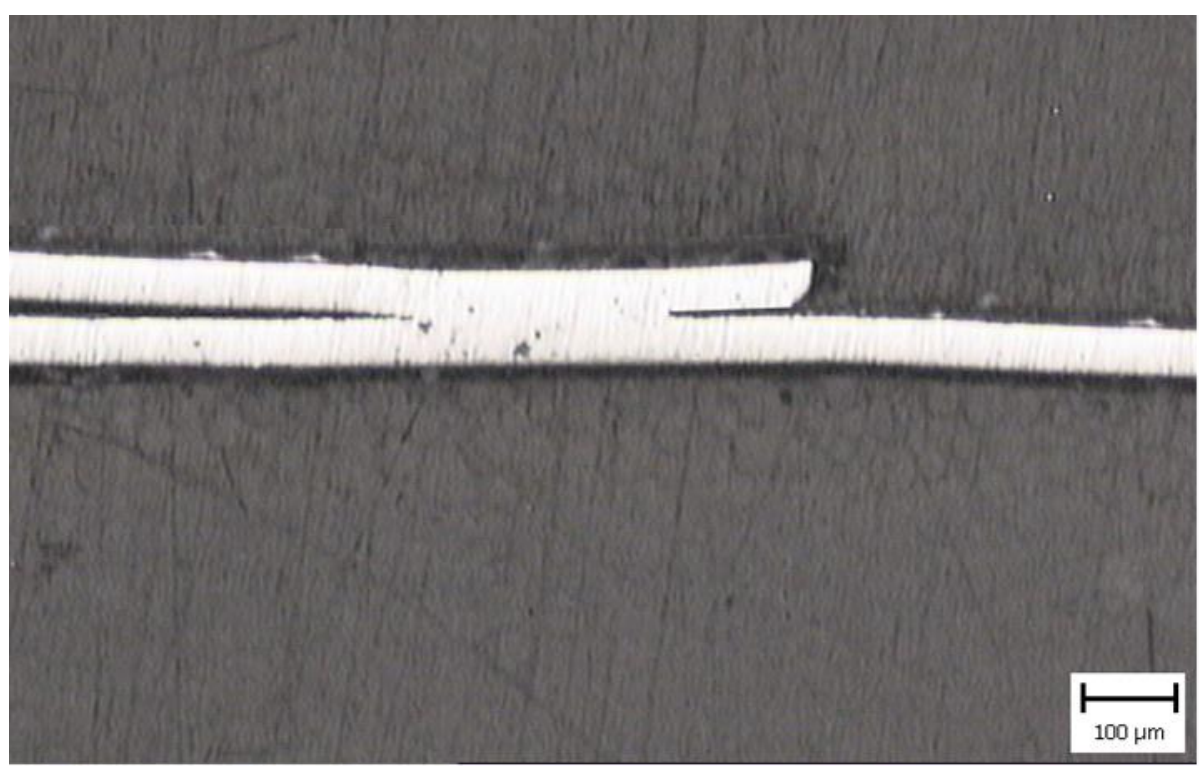

Figure 3 The macro graphic of the welded joint 
The assessment of the mechanical strength of the welded joints was made by static traction tests and unbutoning of the welded points. Figure 4 exemplifies a traction curve, and Figure 5 shows the result of a debugging attempt. As expected, the breaking strength of the welded kernel is high, $R_{m}=422 \mathrm{MPa}$, but the plasticity reserve is low. In the case of debuting tests, the condition for accepting the welds is that the welded kernel is torn from a component without detaching it. From Figure 4 it can be seen that the rupture of the material occurred around the welded point, which attests to a good quality of the joints made.

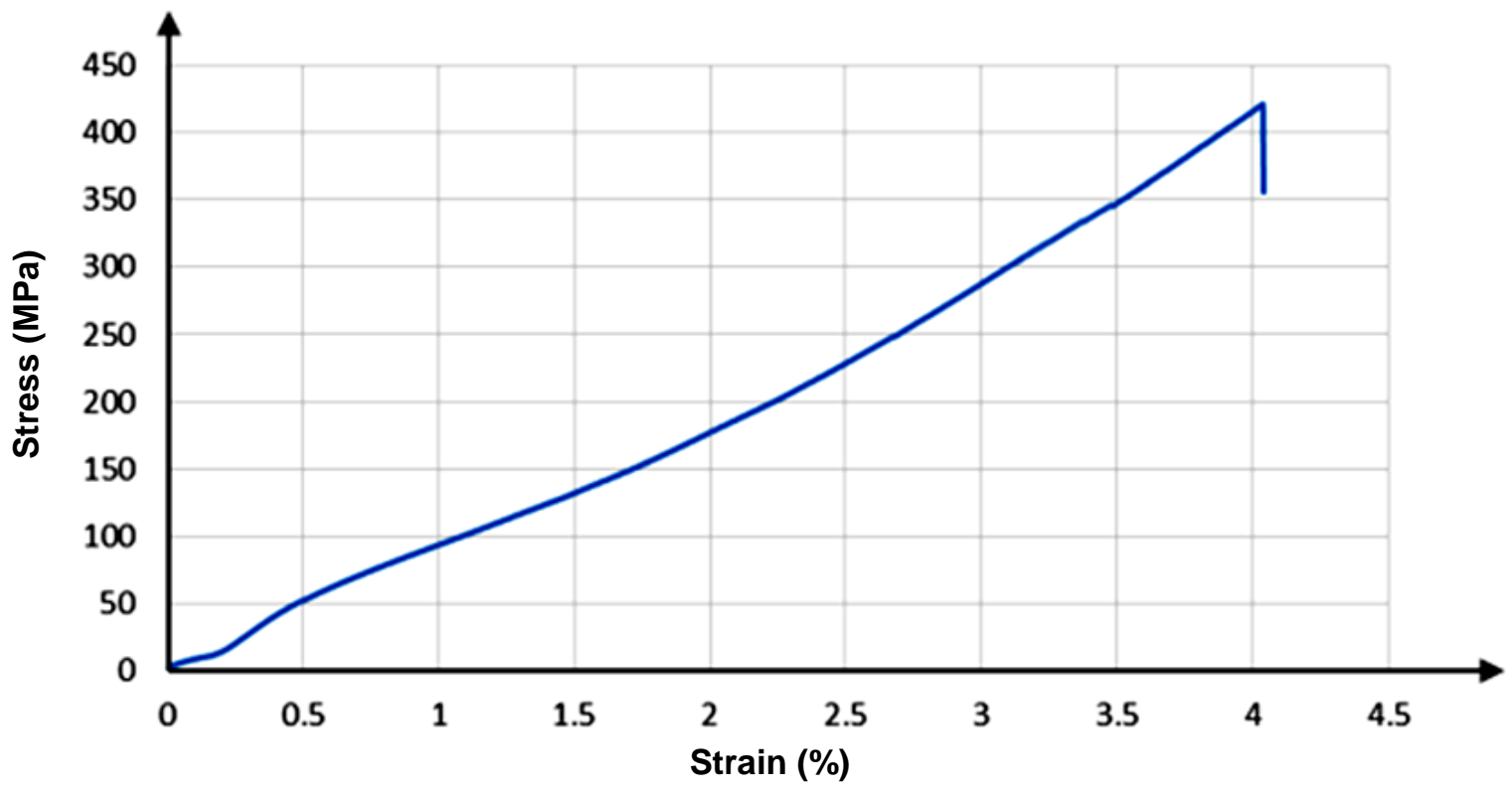

Figure 4 The stress - strain curve
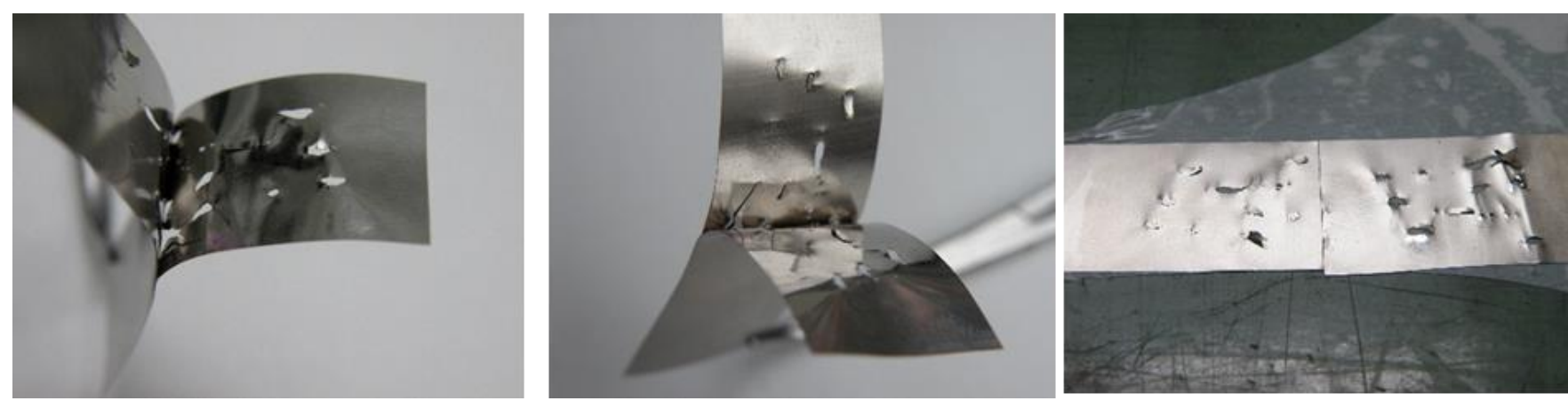

Figure 5 The appearance of rupture by unbutoning

To investigate the influence of the welding process on the maintainers of a high degree of amorphization of the welding core, DSC analyzes were performed on both the base material (cast foil) and the welded joint. The NETZSCH STA Jupiter 449F1 instrument and the following working parameters were used for the experiments:

- $\quad$ base metal sample mass: $8 \mathrm{mg}$;

- $\quad$ welded joint test mass: $8 \mathrm{mg}$;

- $\quad$ heating speed Vi: $20 \mathrm{~K} / \mathrm{min}$;

- crucibles: $\mathrm{Al}_{2} \mathrm{O}_{3}$;

- atmosphere: $\mathrm{N}_{2}$ purge: $50 \mathrm{ml} / \mathrm{min}$; purge protection: $20 \mathrm{ml} / \mathrm{min}$.

The DSC curves recorded for these experimental conditions are shown in Figure 6, and the results obtained look like this: 
- For the base metal in the cast state: $T_{g}=465^{\circ} \mathrm{C} ; T_{x}=485^{\circ} \mathrm{C} ; \Delta H=19.16 \mathrm{~J} / \mathrm{g}$ (enthalpy of crystallization); - For the welded joint: $T_{g}=465^{\circ} \mathrm{C} ; T_{x}=485^{\circ} \mathrm{C} ; \Delta H=15.09 \mathrm{~J} / \mathrm{g}$ (crystallization enthalpy).

It can be concluded that in the welded joint the amorphous structure is preserved, as appears or a slight increase of the glass transition temperature and a slight decrease of the crystallization enthalpy, because of a beginning of structural relaxation.

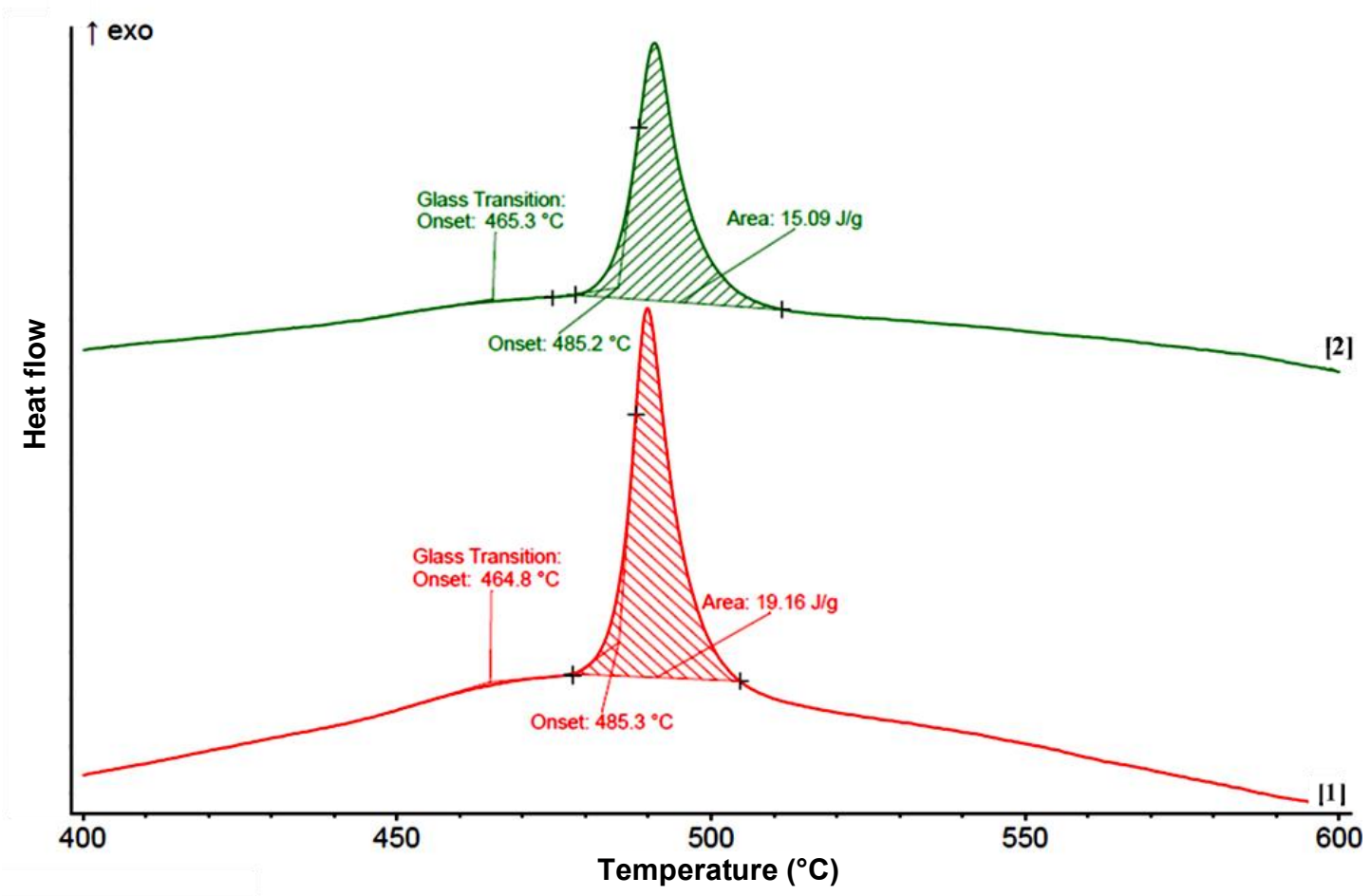

Figure 6 DSC curves for base material (1) and for welding spot (2)

\section{CONCLUSION}

Welding of thin sheets of foil type involves the use of welding processes that allow a very precise control of the energy introduced into the components to avoid burning the material with its penetration.

Welding with energy stored in capacitors is an ideal process for pressure welding of foils precisely due to the very precise dosing of the energy and the possibilities of regulation in very wide and at the same time easy limits.

Welding of amorphous foils presents an additional difficulty due to the specific properties and mainly the high electrical resistivity.

Experimental research, analysis and tests confirm the possibility of successful welding of amorphous foils from $\mathrm{Ni}_{68} \mathrm{Fe}_{3} \mathrm{Cr}_{7} \mathrm{Si}_{8} \mathrm{~B}_{14}$ with a thickness of $50 \mu \mathrm{m}$ using spot welding with energy stored in capacitors.

\section{REFERENCES}

[1] YOSHIHIKO Y., ATSUSHI K., KENZO F., AKIHISA I. Oxygen embrittlement and effect of the addition of $\mathrm{Ni}$ element in a bulk amorphous Zr-Cu-Al alloy. Materials Transactions. 2002, vol. 43, pp. 571-574.

[2] LI, A B., LI, Z.Y., XIONG, J.G., XING, L., WANG, D., LI, Y. Laser welding of Zr45Cu48AI7 bulk glassy alloy. Journal of Alloys and Compounds. 2006, vol. 413, pp.118-121. 
[3] LIU, S.D., LIU, K.X., CHEN, Q.Y., WANG, J.T., YAN, H.H., LI, X.J. Metallic glass coating on metals plate by adjusted explosive welding technique. Applied Surface Science. 2009, vol. 255, issue 23, pp. 9343-9347.

[4] SWISTON jr., A.J., HUFNAGEL, T.C., WEIHS, T.P. Joining bulk metallic glass using reactive multilayer foils. Scripta Materialia. 2003, vol. 48, issue 12, pp. 1575-1580.

[5] DRAGANESCU, D., CODREAN, C., BUZDUGAN, D., SERBAN, V.-A., MITELEA, I. Processing and characterization of Ni63Cr12Fe4Si8B13 amorphous alloy for the manufacturing of electrical resistances. Materials Today: Proceedings. 2021, vol. 45, issue 5, pp. 4367-4371. 